\title{
Density and population estimates of Amani Sunbird Anthreptes pallidigaster in Kenya's Arabuko-Sokoke Forest
}

\author{
JEFFREY A. DAVIS
}

\section{Summary}

The Arabuko-Sokoke Forest (ASF) is the largest area of coastal forest remaining in East Africa. However, encroachment and habitat degradation threaten the existence of many plant and animal species, including the East African endemic Amani Sunbird Anthreptes pallidigaster. The aim of this study was to arrive at an estimate of population size for Amani Sunbirds within the ASF. Forty transects were surveyed over 3 months in 1999. The total length of all transects was $63.572 \mathrm{~km}$. In total, 103 Amani Sunbirds were detected at an estimated density of $36.6 \mathrm{birds} / \mathrm{km}^{2}$. Thus with a total area of $77 \mathrm{~km}^{2}$, the Brachystegia woodland of the ASF should hold about 2,818 Amani Sunbirds. This estimate is much lower than the 5,800-9,400 birds estimated by Britton and Britton (1978). While it is possible that their estimate was inaccurate, the apparent decline in the population could be due to natural population fluctuations. Habitat degradation is another possible cause, as illegal logging and tree-felling continue in and around the ASF. Since the majority of the local people around the ASF are farmers, there is little concern for the welfare of the forest, especially when they see few benefits stemming from conserving the resource. Future funding towards the conservation of the ASF should focus on (I) setting up a consistent monitoring programme that will provide further population estimates for endangered species such as Amani Sunbird, and (2) ensuring that local people get some benefit.

\section{Introduction}

The natural fragmentation of landscapes has been exacerbated by human activities, such as forest clear-cutting and development of land for agricultural purposes (Bender et al. 1998). Increased habitat fragmentation through human activity has had a devastating effect on species diversity, and the rate of human-induced extinction is likely to increase (Wilson 1989). This is especially true of tropical forests in developing countries (Aleixo 1999).

The Arabuko-Sokoke Forest (ASF), situated just inland from the Kenyan coast, faces a major threat from increased forest clearance (Britton and Zimmerman 1979, Kelsey and Langton 1984, Bennun and Njoroge 1999). Representing one of East Africa's few remaining areas of coastal lowland forest, it is the stronghold for five globally Endangered bird species, including the East African endemic Amani Sunbird Anthreptes pallidigaster (BirdLife International 2000). Despite its conservation status, the population biology of Amani Sunbird has been largely ignored. Although other populations exist in Tanzania's Usambara and Udzungwa mountains (Zimmerman et al. 1996, Evans 1997, Dinesen et al. 1993), their size and distribution are little understood. 
The purpose of my study was to obtain density and population estimates of Amani Sunbirds within the ASF based on distance sampling techniques (sensu Buckland et al. 1993). Distance theory differs from classical finite population sampling theory (Cochran 1977) in two ways: (I) the size of the sample area is not always known, and (2) many objects may go undetected (Buckland et al. 1993). I used the line transect method to collect data on the distribution and abundance of Amani Sunbirds.

\section{Methods}

\section{Study area}

The ASF is about $100 \mathrm{~km}$ north of Mombasa, within the Kilifi District of Kenya's Coast Province, and occupies about $400 \mathrm{~km}^{2}$. Although only $43 \mathrm{~km}^{2}$ of the forest has been designated as a Nature Reserve, it is the largest forest reserve and contains the greatest area of complete natural forest cover in coastal Kenya (Robertson and Luke 1993). The altitude ranges from sea level to c. $210 \mathrm{~m}$ near the south-west corner (Figure I). Most of the ASF is low, with elevation rising barely more than $60 \mathrm{~m}$ (Robertson and Luke 1993).

Described as a lowland evergreen dry forest (Britton and Zimmerman 1979, Kelsey and Langton 1984), it has several distinct plant communities:

(i) Dense forest, composed of Hymeneae verrucosa and Croton pseudopulchellus $\left(7 \mathrm{~km}^{2}\right)$.

(ii) Mixed Forest, a semi-deciduous dense forest type on white sandy soils, covering c. $63 \mathrm{~km}^{2}$. The major tree species include Combretum schumannii, Afzelia quanzensis, Hymeneae verrucosa and Manilkara sansibarensis. Average canopy height is 10-12 m (Britton and Zimmerman 1979, Kelsey and Langton 1984)

(iii) Evergreen Forest, dominated by Cynometra webberi, Manilkara sulcata and Brachylaena hutchinsii (Britton and Zimmerman 1979), growing above $60 \mathrm{~m}$ a.s.l. on distinctive red loam called "margarini" sand soil. The canopy ranges in height from $15 \mathrm{~m}$ to $4 \mathrm{~m}$ or less (Britton and Zimmerman 1979).

(iv) Brachystegia woodland, or Miombo, as found throughout southern Africa, covering c. $77 \mathrm{~km}^{2}$ and consisting mainly of Brachystegia spiciformis (Britton and Zimmerman 1979). This forest type is open woodland, with herbaceous ground-cover and scattered shrubs. Canopy height reaches up to $18 \mathrm{~m}$, but canopy cover rarely exceeds 50\% (Britton and Zimmerman 1979), and mean distance between trees is $16.4 \mathrm{~m}$ (Moomaw 1960). Other tree species include Hymeneae verrucosa, Haplocoelum inoploeum and Polyalthia stuhlmanii.

Further information on the structure and composition of the ASF can be found in Kelsey and Langton (1984).

\section{Survey techniques}

Between 19 February and 22 April 1999, I surveyed 40 different transects, eight of which were surveyed twice. For logistic reasons, I selected transects from a network of paths used by native people moving through the forest and animals moving within the forest. Transects were chosen so that the Brachystegia woodland was systematically surveyed. Several transects $(n=4)$ were also placed in Mixed Forest habitat to assess abundance of Amani Sunbirds within this forest type. 


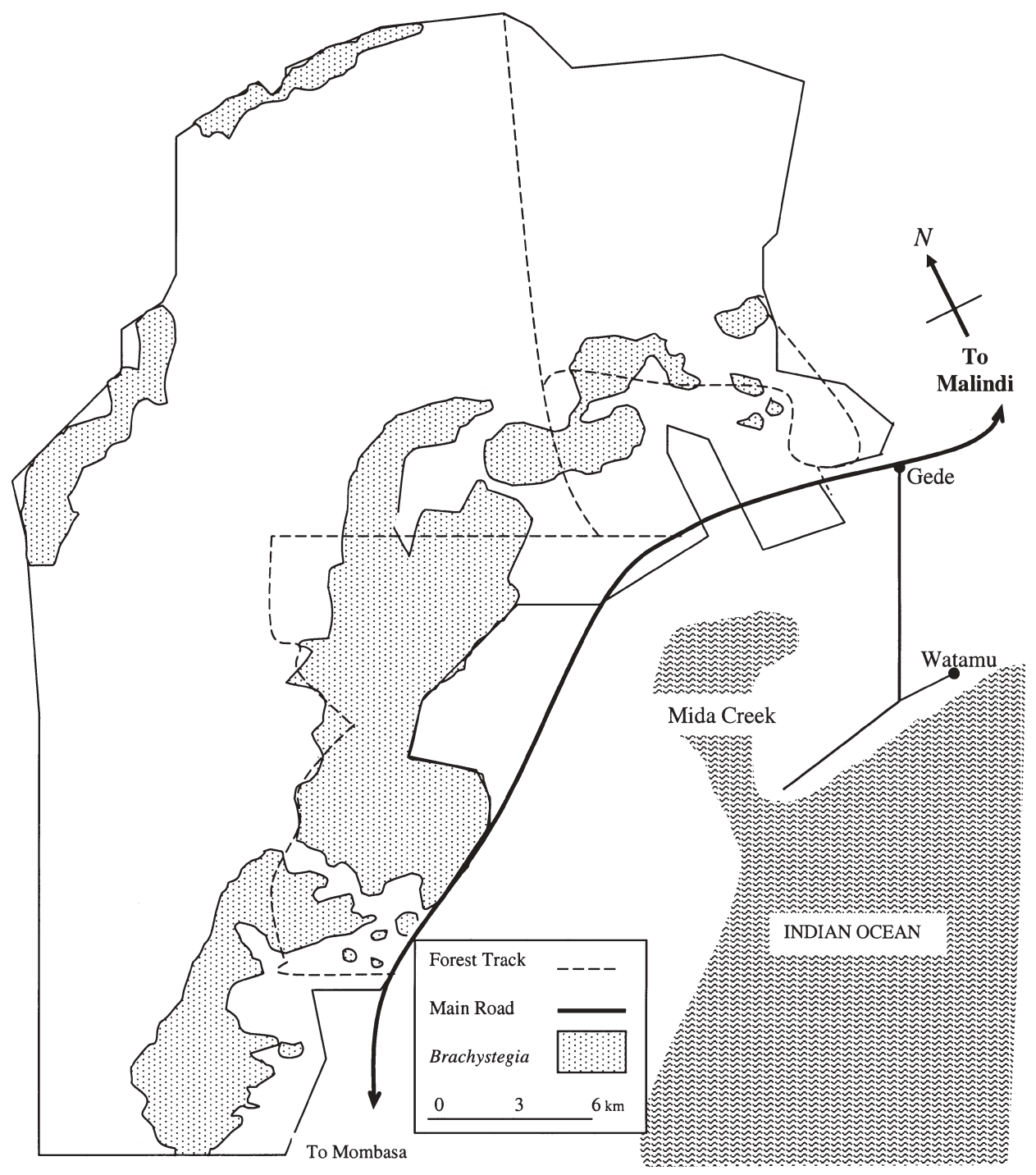

Figure 1. The Arabuko-Sokoke Forest (ASF) is located near Gede, just inland from Kenya's coast and $110 \mathrm{~km}$ north of Mombasa. Cynometra and Mixed Forest make up most of the area of the ASF, but they are not illustrated here. Amani Sunbird is a habitat specialist, being found primarily in Brachystegia woodland, which covers a total area of $77 \mathrm{~km}^{2}$. The various Brachystegia patches are illustrated; they were surveyed using line transects.

All surveys were carried out between o7hoo and I1hoo, and only when light and weather conditions were favourable for observation. Rate of movement varied from I to $1.5 \mathrm{~km} / \mathrm{h}$, including occasional stops for watching and listening. Although some movement backward along transects was necessary to confirm a detection, reverse movement did not exceed $50 \mathrm{~m}$. I recorded detection cue (sight and/or call), sex (if possible), behaviour, and perpendicular distance of the bird from each transect. All distances were estimated or paced if ground-cover permitted. Before collecting data for 
the survey, I spent I month in the field practising distance estimation (verified by actual measurement) and becoming familiar with Amani Sunbird's call. Distance data were analysed using DISTANCE 3.5 software (Thomas et al. 1998).

\section{Results}

The total length of all transects was $63.572 \mathrm{~km}$; transects varied in length from $210 \mathrm{~m}$ to $4,000 \mathrm{~m}$ (mean $1,300 \mathrm{~m}$ ). Roads were rarely used as transects $(n=5 ; 4,450 \mathrm{~m}$ total). Although I surveyed the Mixed Forest (c. 5,500 m of transects), the sample size of sunbirds detected $(n=3)$ was too small to warrant data analysis.

Amani Sunbirds were often found feeding with mixed-species flocks. In a sample of 27 sunbirds, $14(52 \%)$ were found foraging with other species. Some of those $(n=4)$ had two sunbirds in the flock; the rest were all single birds. These flocks were composed of various species, the most common being Collared Sunbird A. collaris, Darkbacked Weaver Ploceus bicolor, Little Yellow Flycatcher Erythrocercus holochlorus, Chestnut-fronted Helmet-shrike Prionops scopifrons, Yellow-bellied Greenbul Chlorocichla flaviventris and Pale Batis Batis soror. Slightly more males were detected than females $(61 \%, n=28)$. Often sunbirds were detected by their calls, which were made by both males and females. Singing males were uncommon $(n=4)$ and therefore the data do not refer to a breeding population. That some of the surveys may have extended into the breeding season (late April) was unintentional and I chose not to survey throughout the breeding season due to time constraints.

The total number of sunbirds detected in the Brachystegia woodland was 103. Thus, the encounter rate $(n / L)$ was 1.6 sunbirds $/ \mathrm{km}$. Using the Hazard-Rate Model (Figure 2, Table 2) of DISTANCE estimation (Buckland et al. 1993), the density of

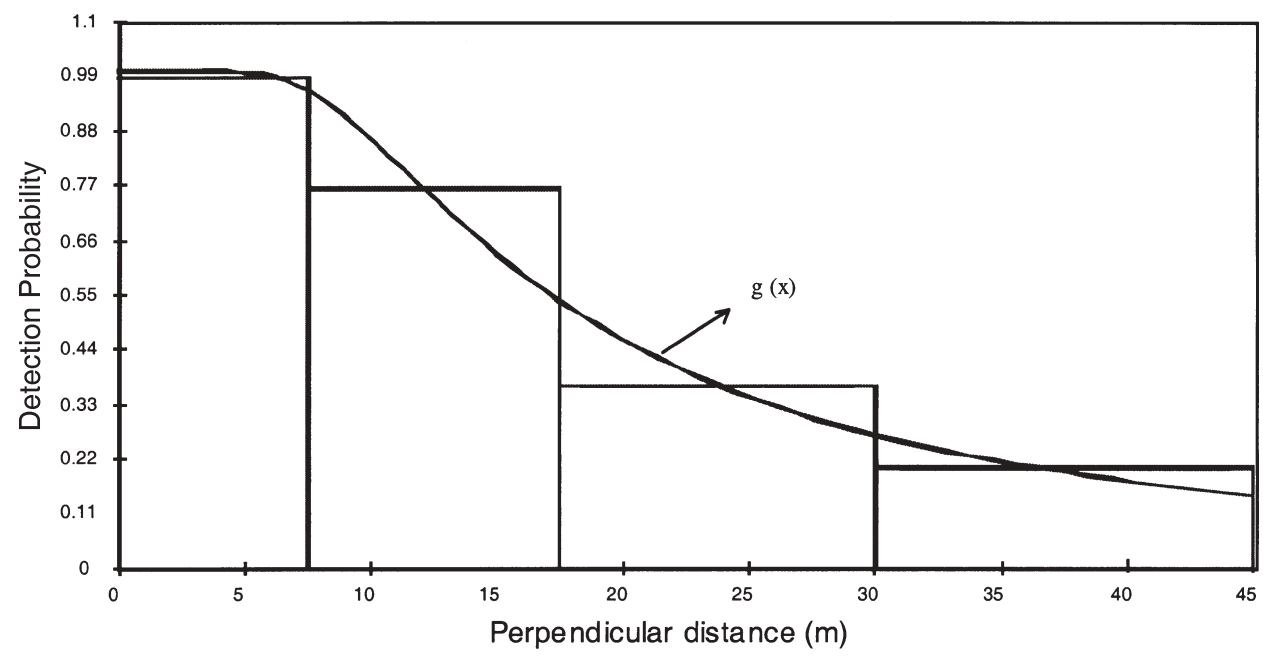

Figure 2. Probability of detecting an Amani Sunbird in relation to perpendicular distance (m) from the transect line. Observed distance data (bars) were grouped into intervals to minimize errors in distance estimation. Expected distances were predicted by the linear function, $g(x)$, using the Hazard-Rate Model. 
Table 1. Goodness-of-fit test comparing the number of Amani Sunbirds actually seen with the number expected.

\begin{tabular}{llll}
\hline Distance intervals $(\mathrm{m})$ & Observed values & Expected values & Chi-square values \\
\hline $0.0-7.5$ & 34.0 & 34.3 & 0.002 \\
$7.5-17.5$ & 35.0 & 34.3 & 0.015 \\
$17.5-30.0$ & 21.0 & 21.9 & 0.033 \\
$30.0-45.0$ & 14.0 & 13.6 & 0.012 \\
\hline
\end{tabular}

Expected values were calculated by DISTANCE, using the Hazard-Rate Model (see Figure 2).

The differences were non-significant $\left(\chi^{2}=0.06, \mathrm{df}=1, P=0.80\right)$.

Table 2. Criteria used to select the Hazard-Rate Cosine Model for density and population estimates, compared with two other Cosine models generated by DISTANCE.

\begin{tabular}{lllll}
\hline Model & AIC & $\% \mathrm{CV}$ & Chi-square values $(\mathrm{df}=1)$ & Density $\left(\mathrm{birds} / \mathrm{km}^{2}\right)$ \\
\hline Hazard-Rate & 279.67 & 24.68 & $\chi^{2}=0.06, P=0.80$ & 36.6 \\
Half-Normal & 279.50 & 21.33 & $\chi^{2}=1.85, P=0.40$ & 33.7 \\
Uniform & 279.62 & 22.45 & $\chi^{2}=0.02, P=0.89$ & 37.8 \\
\hline
\end{tabular}

The chi-square value is the sum of the differences between observed and expected values across four distance intervals (see Table 1 ).

Amani Sunbirds was estimated as $36.6 \mathrm{birds} / \mathrm{km}^{2}$. With a total area of $77 \mathrm{~km}^{2}$, the Brachystegia should hold about 2,818 sunbirds (95\% CI: 1,739-4,565). These values were obtained with observations being grouped into distance intervals (Table I). If ungrouped data were used, density and population estimates were slightly higher (38.4 birds $/ \mathrm{km}^{2}$ and 2,953 birds, respectively).

The Hazard-Rate Cosine Model was chosen based on various criteria discussed in depth by Buckland et al. (1993). These include the comparison of observed versus expected values, coefficient of variation (\% CV), and Aikeke's Information Criterion (AIC). The number of sunbirds observed in all the distance intervals closely matched those expected (Table I). The Hazard-Rate Model had an AIC value of 279.67 and a \% CV value of $24.68 \%$ (Table 2). Although other models, such as the Half-Normal Cosine, had lower \% CV values $(21.3 \%)$, it is the fit of the line near transects that is most important (Buckland et al. 1993); thus the Hazard-Rate model was selected.

\section{Discussion}

\section{Distance analysis}

Distance analysis makes three assumptions that must be met:

(i) $g(0)$, the probability of detecting an object at zero distance, will equal 1.o. Based on experience in the field with Amani Sunbirds, it is unlikely that any sunbirds on transects went undetected. Being largely insectivorous and foliage gleaners (Zimmerman et al. 1996), they are very active birds and are easily detected, especially as they fly from tree to tree giving a distinctive "seer-seer" call (Britton and Britton 1978). Also, the Brachystegia trees were on average $16.4 \mathrm{~m}$ apart and the foliage was not dense (Moomaw 1960) so birds were less likely to go unnoticed than would understorey birds. However, it is not possible to be certain that no birds went undetected. In such a case, density would be underestimated. 
(ii) There is no movement prior to detection (due to the presence of an observer). This was not a likely source of error, simply because Amani Sunbirds feed high in the canopy and are not shy or wary of human presence (pers. obs.). Movement towards the observer, which would bias density estimates high, was never observed. Movement away from the observer, while a more likely violation of the assumption, was not observed but, if it did occur, density would be underestimated.

(iii) Distances are measured without error. This is the most likely assumption to have been violated in this study. However, transect length was an unlikely source of error because transects were carefully measured to the nearest metre using premeasured lengths of rope. Perpendicular distances were more prone to error, and thus distance data were grouped into four intervals (Table 1 ). Following Buckland et al. (1993), interval width increased progressively with distance from transects, allowing more room for error among longer distance estimates. Although distances could have been underestimated (which would bias estimates high), overestimation of distances is more likely when using visual estimation (Buckland et al. 1993), and thus density estimates would be biased low. Therefore, violations of all three assumptions would tend to underestimate Amani Sunbird density and population size, so my estimate is conservative.

Considering the sample size of this study $(n=103)$, it might have been possible to conclude the fieldwork in less than 3 months yet still produce reliable estimates. To test the effect of decreasing sample sizes on density estimates and population size confidence intervals $(95 \% \mathrm{CI})$, I reduced the number of detections by 10 at a time and re-ran the analyses. Density estimates varied between 36 and 32 birds $/ \mathrm{km}^{2}$ as sample size was reduced to 60 sunbirds, but dropped sharply beyond this point. For example, if only 30 birds had been detected, density and population estimates would have been 22.8 and 1,759, respectively. The $95 \%$ CI generally increased with a reduction in sample size, but peaked at $n=70$. In other words, as sample size increased (from $n=70$ to $n=103$ ), confidence intervals became narrower (though not in a linear pattern). For instance, at $n=70$, the $95 \%$ CI was 4,861 , while at $n=103$ it was 2,925 . This implies that a large sample size is important but that there might be a point where the cost of a study is no longer justified by the precision given by increasing sample size.

\section{Previous research}

In terms of data collection and methodology, there are few studies at the ASF that can be compared to this one. Fanshawe (1995) studied the effect of logging on numerous species within the ASF, including Amani Sunbird, but did not collect density data. Of 187 sunbirds, he found that most $(87 \%)$ were found in mixed-species flocks. My study, on the other hand, found roughly $50 \%$ of sunbirds in mixed-species flocks. Although my sample size $(n=27)$ was much smaller, an earlier study by Britton and Britton (1978) found that Amani Sunbirds were found with other species less than $20 \%$ of the time. Since the end of my study coincided with the rains, it could be that sunbirds forage less with other species during the breeding season, although I have no data to test this. 
Britton and Britton (1978) also collected data on density, with numbers ranging from I pair per 1.5 ha to I pair per 2.4 ha. They estimated the population at between 2,900 and 4,700 pairs, i.e. between 5,800 and 9,400 birds. Although my estimate is probably conservative, my study suggests a much smaller population. Such a discrepancy between these two surveys could be due to an inaccurate estimate. Britton and Britton's estimate was derived using a reliable method (see Emlen 1977) but they had fewer transects $(n=24)$ and surveyed in just four sites. A sample size is not given nor was their study focused on density estimation. A study that used both Emlen's methods and distance methods, but with equal sample effort, could be carried out to address this. If the two methods produced significantly different estimates, then one cannot be sure whether the sunbird population actually changed between 1978 and 1999 and the problem may then be with the sampling technique. If similar estimates were derived, an alternative hypothesis would be that Britton and Britton's estimate was in fact fairly accurate and the number of sunbirds has declined.

\section{Habitat loss}

The decline of many species has been directly correlated with fragmentation and loss of habitat (Schumaker 1996), a good example being bird species in fragmented Brazilian forests (Willis 1979). The Atlantic Forest in southeastern Brazil has been seriously degraded and as a result is one of the most threatened habitats in the world (Aleixo 1999). Not surprisingly, bird populations are among the most threatened in the Neotropics, with many species facing unpredictable futures (Aleixo 1999).

Forests are the most threatened habitats in Kenya (Fanshawe and Bennun 1991) with $63 \%$ of globally threatened bird species being dependent on forests (Collar et al. 1994, Bennun et al. 1997). Potential threats to Kenyan forests include encroachment, logging and poaching of trees for charcoal, woodcarvings and furniture (Bennun and Njoroge 1999). Clear evidence for this was found during a recent survey of the Dakatcha-Marafa Forests north of Malindi (J. Davis and Colin Jackson, unpubl. data 2001). Numerous Brachystegia trees were being felled by local people, who stated that the District Officer gave them permits after they paid a small fee. As a result, there were very few large Brachystegia trees remaining in those areas. It is interesting to note that no Amani Sunbirds were detected in those areas.

Fortunately, the ASF has been under greater protection than the forests north of Malindi. Although illegal activities still continue (Bauer 2001), these may be kept to a minimum by the presence of Kenya Wildlife Service patrols, Forest Guides and ongoing research projects. The largest tract of Brachystegia is accessible by just one road (Figure 1 ) and frequent visits by tourists, researchers and Forest Guides may discourage tree poachers from harvesting large trees by lorry as they do elsewhere (e.g. in the Dakacha-Marafa area), or within other areas of the ASF. Furthermore, Brachystegia is more open than Cynometra or Mixed Forest, making any person conducting illegal activities much more conspicuous.

In one of his study plots, Fanshawe (1995) found that Amani Sunbirds were absent and this appeared to be due to habitat degradation, suggesting they are sensitive to habitat change, at least within the Brachystegia of the ASF. This sensitivity could explain why no sunbirds were detected on 10 transects (total distance $12,877 \mathrm{~m}$ ). 
Although I did not observe any logging on a large scale in the Brachystegia woodland, Amani Sunbirds may be sensitive to slight changes in the habitat. This may not be the case in Tanzania, where they seem to be more tolerant of habitat degradation (Evans 1997). Other species in the ASF may be more tolerant as well; Fanshawe (1995) noted that in terms of bird species in general, little had changed since Britton and Zimmerman's (1979) study years earlier. Although Fanshawe did mention that three forest-dependent species (African Broadbill Smithornis capensis, African Pitta Pitta angolensis, Green-headed Oriole Oriolus chlorocephalus) were not recorded during his study, all three have been sighted within the ASF in 2001 (Colin Jackson, Emmanuel Thoya and David Ngala, pers. comm.). Without a better understanding of the local movements of a species, it is difficult to deduce the reason(s) for a species' absence or potential decline. This is especially critical for a species like Amani Sunbird, which seems restricted to primary Brachystegia woodland.

\section{Population fluctuation}

A decline in the population of Amani Sunbirds could be due to natural fluctuations. The exact cause(s) of the fluctuations, however, are unknown and should be addressed by future studies. Parameters such as population size, density and rate of population change are known to exhibit spatial and temporal variation and are often affected by environmental factors (Pimm et al. 1988). In addition, small populations are susceptible to demographic accidents, changes in birth and death schedules, and fluctuations in sex ratios (Pimm et al. 1988). As insectivores, Amani Sunbirds are presumably affected by insect populations that are dependent on the African rains, which are often unpredictable. Future research, therefore, should take into consideration past and present environmental factors, such as droughts and annual rainfall.

\section{Conclusion}

Data from this study suggest that the population of Amani Sunbirds in the ASF is small and limited to a small area. The population could be declining from habitat loss, going through a natural population cycle, or both. Regardless of whether the first population estimate was accurate, the important issues now are (i) the continued protection of the habitat that is left, and (ii) the implementation of a consistent monitoring programme so that we have more reliable data on population size.

Complete protection of the Brachystegia and other plant communities within the ASF will be difficult, if not impossible, unless one involves the people living around the forest. The most important problems facing threatened species are habitat loss and degradation (Collar et al. 1994, Bennun 1999), which are ultimately caused by humans. This is a serious problem in Africa, where populations are expanding rapidly and poverty forces many people to look for alternative sources of income, such as tree-felling and charcoal-burning (pers. obs.). Unfortunately, those in power and capable of implementing community development projects are often ignorant of environmental issues and their long-term impact on local people. What is needed is a community-based initiative - perhaps funded initially from outside sources - that uses eco-tourism to benefit local people and protect the habitat being threatened. As Bennun (1999) argues, this concern by native people for the welfare of a particular site can provide enormous weight to any conservation effort. 


\section{Acknowledgements}

I thank Leon Bennun and the Department of Ornithology staff, National Museums of Kenya for guidance with this study and granting permission for it to proceed. Au Sable Environmental Institute (U.S.A.) provided financial support and seconded me as an intern to A Rocha Kenya. Colin Jackson provided advice and logistical support, while the late Barbara Simpson and staff of Simpson's guesthouse provided hospitable accommodation. Art and Mary Ellen Davis generously loaned me a vehicle. The following organizations and individuals provided funding: Asbury United Methodist Church, Media Presbyterian Church, Turtle Bay Beach Club, and Dr and Mrs John Stauffer.

\section{References}

Aleixo, A. (1999) Effects of selective logging on a bird community in the Brazilian Atlantic Forest. Condor 101: 537-548.

Bauer, C. R. (2001) Commercial and subsistence impacts on the Arabuko-Sokoke Forest, in coastal Kenya, using an endemic mammal as an indicator species. MS thesis, University of Western Kentucky, U.S.A.

Bender, D. J., Contreras, T. A. and Fahrig, L. (1998) Habitat loss and population decline: a meta-analysis of the patch size effect. Ecology 79: 517-534.

Bennun, L. A. (1999) Threatened birds and rural communities: balancing the equation. Pp. 1546-1555 in N. J. Adams and R. H. Slotow, eds. Proc. Int. Ornithol. Congr. Durban.

Bennun, L. A. and Njoroge, P. (1999) Important Bird Areas in Kenya. Nairobi: East Africa Natural History Society.

Bennun, L. A., Dranzoa, C. and Pomeroy, D. E. (1997) The forest birds of Kenya and Uganda. J. East Afr. Nat. Hist. 85:23-48.

BirdLife International (2000) Threatened birds of the world. Barcelona and Cambridge, U.K.: Lynx Edicions and BirdLife International.

Britton, P. L. and Britton, H. A. (1978) Notes on the Amani Sunbird Anthreptes pallidigaster including a description of the nest and eggs. Scopus 2: 102-103.

Britton, P. L. and Zimmerman, D. A. (1979) The avifauna of Sokoke Forest, Kenya. J. East Afr. Nat. Hist. Soc. Natl. Mus.169: 1-15.

Buckland, S. T., Anderson, D. R., Burnham, K. P. and Laake, J. L. (1993) Distance sampling: estimating abundance of biological populations. London: Chapman and Hall.

Cochran, W. G. (1977) Sampling techniques. Third edition. New York: Wiley.

Collar, N. J., Crosby, M. J. and Stattersfield, A. J. (1994) Birds to watch 2: The world list of threatened birds. Cambridge, U.K.: BirdLife International.

Connell, J. H. and Sousa, W. P. (1983) On the evidence needed to judge ecological stability or persistence. Am. Nat. 121: 789-824.

Dinesen, L., Lehmberg, T. Svendsen, J. O. and Hansen, L.A. (1993) Range extension and other notes on some restricted-range forest birds from West Kilombero in the Udzungwa Mountains, Tanzania. Scopus 17: 48-59.

Emlen, J. T. (1977) Estimating breeding season bird densities from transect counts. Auk 94: $455-468$.

Evans, T. D. (1997) Records of birds from the forests of the East Usambara lowlands, Tanzania, August 1994-February 1995. Scopus 19: 92-108.

Fanshawe, J. (1995) The effect of selective logging on the bird community of Arabuko-Sokoke Forest, Kenya. DPhil thesis, University of Oxford, U.K.

Fanshawe, J. and Bennun, L. A. (1991) Bird conservation in Kenya: creating a national strategy. Bird Conserv. Internatn. 1: 293-315. 
Kelsey, M. G. and Langton, T. E. S. (1984) The conservation of the Arabuko-Sokoke Forest, Kenya. Cambridge, U.K.: ICBP (International Council for Bird Preservation Study Report No. 4).

Moomaw, J. C. (1960) A study of the plant ecology of the coast region of Kenya Colony, British East Africa. Nairobi: Government Printer.

Perrins, C. M. and Birkhead, T. R. (1983) Avian ecology. Glasgow: Blackie.

Pimm, S. L., Jones, H. L. and Diamond, J. M. (1988) On the risk of extinction. Am. Nat. 132: $757-785$.

Robertson, S. A. and Luke, W. R. O. (1993) The Report of the NMK/WWF Coast Forest Survey. WWF Project 3256: Kenya, Coast Forest Status, Conservation and Management, Kenya Indigenous Forest Conservation Programme.

Schumaker, N. (1996) Using landscape indices to predict habitat connectivity. Ecology 77: 1210-1225.

Sinclair, A. R. E. (1989) Population regulation in animals. Pp. 197-241 in J. M. Cherrett, ed. Ecological concepts: the contribution of ecology to an understanding of the natural world. 29th Symposium of the British Ecological Society. Oxford: Blackwell Scientific.

Thomas, L., Laake, J. L., Derry, J. F., Buckland, S. T., Borchers, D. L., Anderson, D. R., Burnham, K. P., Strindberg, S., Hedley, S. L., Burt, M. L., Marques, F., Pollard, J. H. and Fewster, R. M. (1998) DISTANCE 3.5. Research Unit for Wildlife Population Assessment, University of St Andrews, U.K.

Willis, E. O. (1979) Species reductions in reminiscent woodlots in southern Brazil. Proc. Int. Ornithol. Congr XVII: 783-786.

Wilson, E. O. (1989) Threats to biodiversity. Sci. Am. 261: 108-115.

Zimmerman, D. A., Turner, D. A. and Pearson, D. J. (1996) Birds of Kenya and northern Tanzania. South Africa: Russel Friedman.

JEFFREY A. DAVIS

6147 Old Post Road, Kalamazoo, MI 49oo9, U.S.A. (e-mail: nyamachoma@hotmail.com)

Received 10 August 2003; revision accepted 3 August 2004 